5 Shu K H, Lian J D, Yang Y F, et al. Glomerulonephritis in ankylosing spondylitis. Clin Nephrol 1986; 25: 169-74.

6 Mittal V K, Malhotra K K, Bhuyan U N, Malaviya A N. Kidney involvement in seronegative spondarthritides. Indian J Med Res 1983; 78: 670-5.

7 Tiebosch A T M G, Wolters J, Frederik P F M, et al. Epidemiology of idiopathic glomerular disease: a prospective study. Kidney Int 1987; 32: 112-6.

8 Simon P, Ang K S, Bavay P, Cloup C, Mignard J P, Ramee M P. Glomérulonéphrite à immunoglobulines A. Epidémiologie dans une population de 250,000 habitants. Presse Med 1984; 13: $257-60$.

\section{Alterations in appendicular skeletal mass in patients with rheumatoid arthritis, psoriatic arthritis, and osteoarthritis}

SIR, Cooper $e t$ al in their recent article on skeletal mass in rheumatoid arthritis, psoriatic arthritis, and osteoarthritis stated that lumbar bone mass is reduced in rheumatoid arthritis, irrespective of corticosteroid treatment. ${ }^{1}$

For this statement they quoted, without any personal experience, one published reference. ${ }^{2}$ In our opinion, however, this statement does not reflect the results of other reports concerning lumbar bone mass in rheumatoid arthritis. From the same author as the one referred to by Cooper $e$ al there is a previous study of early rheumatoid arthritis, in which no diminution of bone mass could be shown when patients with rheumatoid arthritis were compared with controls. ${ }^{3}$ In our own study we found a normal lumbar bone mass when female, postmenopausal patients with rheumatoid arthritis were compared with controls matched for sex, age, and menopausal state, irrespective of corticosteroid treatment.

Moreover, when discussing the appendicular skeleton as measured by single photon absorptiometry the authors refer to 'one single study', whereas there are many studies of peripheral bone mass at the radial site in rheumatoid arthritis, treated with corticosteroids or not. ${ }^{4-11}$ Some authors report a decreased peripheral bone mass in rheumatoid arthritis while others do not.

As the assessment of bone mass in arthritis is difficult owing to a variety of interfering factors, such as sex, age, menopausal state, disease activity and duration, local destruction, treatment (especially corticosteroid treatment), I feel that the discussion should have been expanded, with a better use of the available publications and a discussion of current controversies.

Arthritis and Metabolic Bone

A VERSTRAETEN

Disease Research Unit,

K U Leuven, U Z. Pellenberg,

B-3041 Pellenberg,

Belgium

\section{References}

1 Cooper C, Poll V, McLaren M, Daunt S O'N, Cawley M I D. Alterations in appendicular skeletal mass in patients with rheumatoid, psoriatic, and osteoarthropathy. Ann Rheum $D i$. 1988; 47: 481-4

2 Sambrook P N, Eisman J A, Yeates M G, Pocock N A, Eberl S Champion G D. Osteoporosis in rhcumatoid arthritis: safety of low dose corticosteroids. Ann Rheum Dis 1986; 45: 950-3.

3 Sambrook P N, Ansell B M, Foster S, Gumpel J M, Hesp R으 Reeve J. Bone turnover in early rheumatoid arthritis. 2음 Longitudinal bone density studies. Ann Rheum Dis 1985; 44 $580-4$.

4 Verstraeten A, Dequeker J. Vertebral and peripheral bon mineral content and fracture incidence in postmenopausaês patients with rheumatoid arthritis: effect of low dose corticosteroids. Ann Rheum Dis 1986; 45: 852-7.

5 Christansen C, Rodbro P. Skeletal status in patients with rheumatoid arthritis. Acta Med Scand 1975; 198: 453-4. $\vec{\omega}$

6 D'Angelo A, Fabris A, Sartori L, et al. Mineral metabolism and bone mineral content in rheumatoid arthritis. Effect of cortico steroids. Clin Exp Rheumatol 1985; 3: 143-6.

7 Dequeker J, Wielandts L, Koentges D, Nijs J. The assessmento of bone loss in rheumatoid arthritis. Acta Rhumatologica 1980 4: 228-9.

8 Mueller M N. Effects of corticosteroids on bone mineral in rheumatoid arthritis and asthma. $A J R$ 1976; 126: 1300.

9 Nagant de Deuxchaisnes C, De Vogelaer J P, Esselinckx $W_{0}^{0}$ et al. The effect of low dose glucocorticoids on bone mass in rheumatoid arthritis: a cross-sectional and longitudinal studyusing single photonabsorptiometry. In: Alvioli L, Gennari C? Imbimbo $\mathrm{H}$, eds. Glucocorticoid effects and their biologica出 consequences. New York: Plenum Press, 1984: 209-39.

10 Als O S, Godfredsen A, Christiansen C. The effect of glucocorticosteroids on bone mass in rheumatoid arthritis patients. Influence of menopausal state. Arthritis Rheum $1 \% 5$ 28: $369-75$

11 Als O S, Christiansen C, Hellesen C. Prevalence of decre bone mass in rheumatoid arthritis. Relation to añ inflammatory treatment. Clin Rheumatol 1984; 3: 201-8.

SIR, As Dr Verstraeten indicates studies of bone mass a市 different anatomical sites in rheumatoid arthritis have produced conflicting results, and we stated this in oup report. It was not our purpose to write an exhaustive review of published work but to highlight some of the inconsistencies, which are, quite naturally, open to variouş. interpretations. We reported our own measurements of appendicular bone mass in three different polyarthro $\overline{2}$ pathies and considered these to be of interest. Dio Verstraeten's comments on corticosteroid treated patients. do not really apply in this context owing to the deliberat exclusion of such patients from our study.

Rheumatology Unit and C COOPER MRC Environmental Epidemiology Unit, M MCLARE Southampton General Hospital, Southampton SO9 4XY

S O'N DAUNE $M$ I D CAWLEN

Correction: Combined suppressive drug treatment in severe refractory rheumatoid disease: an analysis of the relative effects of parenteral methylprednisolone, cyclophosphac mide, and sodium aurothiomalate. In the paper by Drs $M$ Walters and M I D Cawley (Ann Rheum Dis 1988; 47! 924-9) we regret that the first line of the second paragraph of the Discussion was omitted. The first sentence of this paragraph should have read 'The mode of action of both gold and MP in this situation is not clear'. 